\title{
Is endocarditis prophylaxis for dental procedures necessary?
}

\author{
Kathryn A Taubert, ${ }^{1}$ Walter Wilson ${ }^{2}$
}

\begin{abstract}
${ }^{1}$ American Heart Association, Basel, Switzerland

${ }^{2}$ Mayo Clinic Rochester, Minnesota, USA
\end{abstract}

\section{Correspondence to} Kathryn A Taubert, American Heart Association, Basel, Switzerland, 4051;

kathryn.taubert@heart.org

Accepted 2 February 2017

\section{SLinked}

- http://dx.doi.org/10.1136/ heartasia-2016-010860

\section{CrossMark}

To cite: Taubert KA, Wilson W. Heart Asia 2017:9:63-67.

doi:10.1136/heartasia-2016010810

\begin{abstract}
Objectives Our purpose is to address whether antimicrobial prophylaxis is necessary before certain dental procedures for patients at increased risk for acquiring infective endocarditis (IE).
\end{abstract}

Methods We reviewed recommendations for IE prophylaxis made by the American Heart Association (AHA) from 1995 to the present time. We also compared and contrasted the current recommendations from the AHA, European Society of Cardiology (ESC), United Kingdom's National Institute for Health and Care Excellence (NICE) and a consortium of French organisations. We further reviewed recent papers that have observed the incidence of IE since these current recommendations were published.

Results Beginning in the 1990s, questions were raised about the advisability of using antimicrobial prophylaxis before certain dental procedures to prevent IE. Various groups in Europe and the US were increasingly aware that there were not any clinical trials showing the effectiveness, or lack thereof, of such prophylaxis. In the early to mid-2000s, the AHA, ESC and French consortium published guidelines recommending restriction of prophylaxis before dental procedures to patients with highest risk for developing IE and/or the highest risk for an adverse outcome from IE. The NICE guidelines eliminated recommendations for prophylaxis before dental procedures. Studies published after these changes were instituted have generally shown that the incidence of IE has not changed, although two recent reports have observed some increased incidence (but not necessarily related to an antecedent dental procedure). Conclusion A multi-national randomised controlled clinical trial that would include individuals from both developed and developing countries around the world is needed to ultimately define whether there is a role for antibiotic prophylaxis administered before certain dental procedures to prevent IE.

Infective endocarditis (IE), also called bacterial endocarditis, is a very serious and potentially deadly infection of the heart, particularly damaged/ structurally abnormal heart valves or congenital cardiac anomalies ('predisposing heart disease'). IE is an uncommon infectious disease with an annual incidence ranging from about 2-15 per 100000 personyears in contemporary population surveys. ${ }^{1-5}$ In the pre-antibiotic era, it was uniformly fatal.

Although the pathogenesis of endocarditis is beyond the scope of this paper, the process is outlined briefly here. While the smooth endocardial lining of the heart makes it difficult for the bacteria to adhere to, this smooth surface can become damaged in certain types of congenital or acquired heart disease. Examples of situations of damaged endothelium can include: turbulent flow of blood (such as through a stenotic valve or congenital lesion); the presence of a prosthetic heart valve; or a previous history of IE. When this damage occurs, there is an associated release of substances such as tissue factors and cytokines that in turn leads to formation of a platelet-fibrin thrombus (also referred to as non-bacterial thrombotic endocarditis). At this point, it is not an infectious process. However, when bacteria are introduced into the bloodstream, they can adhere to the platelet-fibrin thrombus and colonise there. The resultant vegetation is IE.

With the introduction of antibiotics into general medical practice around the mid-1900s, recommendations started to be made on their use to prevent endocarditis from occurring. The reasoning for this antimicrobial prophylaxis seemed straightforward - certain bacteria in the bloodstream cause endocarditis; certain medical interventions can introduce these bacteria into the bloodstream; certain antibiotics can usually kill these bacteria; and prevention is preferable to treatment. Thus, in individuals with predisposing heart disease, it seemed reasonable to prescribe antibiotics in situations where certain bacteria would be likely to enter the bloodstream. These 'situations' included various dental and surgical procedures. This paper is restricted to dental procedures and will focus on prophylaxis recommendations issued by the American Heart Association (AHA).

The first AHA recommendations, from their Committee on Prevention of Rheumatic Fever and Bacterial Endocarditis, were published in1955 in a paper titled 'Prevention of rheumatic fever and bacterial endocarditis through control of streptococcal infections'. ${ }^{6}$ These recommendations have been revised nine times; ${ }^{7-15}$ the most recent version ${ }^{15}$ was published in 2007. Over the years, drugs of choice as well as dosage and duration have evolved (see table 1), as have both the cardiac conditions and the dental procedures for which prophylaxis was (or was not) recommended. In earlier years, the oral regimen was administered for up to 5 days, whereas in the more recent recommendations, prophylaxis was limited to one dose prior to the procedure.

Beginning in the latter part of the 20th century, there began to be more and more questions about the advisability for the use of prophylactic antibiotics to prevent endocarditis. Guidelines in general were focusing more on evidence-based medicine, broadly defined by Sackett and colleagues in a 1996 BMJ editorial as '...the conscientious, explicit, 
Table 1 American Heart Association antibiotic regimens for IE prophylaxis before dental procedures, 1955-2007

\begin{tabular}{|c|c|}
\hline Year* $^{*}$ & Primary regimens for dental procedurest \\
\hline $955^{6}$ & $\begin{array}{l}\text { Aqueous penicillin } 600000 \mathrm{U} \text { and procaine penicillin } 600000 \mathrm{U} \text { in oil } \\
\text { containing } 2 \% \text { aluminium monostearate administered intramuscularly } \\
30 \text { min before the operative procedure. }\end{array}$ \\
\hline $1957^{7}$ & $\begin{array}{l}\text { For } 2 \text { days before surgery, penicillin } 200000-250000 \mathrm{U} \text { by mouth four } \\
\text { times per day. On day of surgery, penicillin } 200000-250000 \mathrm{U} \text { by mouth } \\
\text { four times per day and aqueous penicillin } 600000 \mathrm{U} \text { with procaine } \\
\text { penicillin } 600000 \mathrm{U} \text { intramuscularly } 30-60 \text { min before surgery. For } 2 \text { days } \\
\text { after, } 200000-250000 \mathrm{U} \text { by mouth four times per day. }\end{array}$ \\
\hline \multirow[t]{3}{*}{$1960^{8}$} & $\begin{array}{l}\text { Step I: prophylaxis } 2 \text { days before surgery with procaine penicillin } \\
600000 \mathrm{U} \text { intramuscularly on each day. }\end{array}$ \\
\hline & $\begin{array}{l}\text { Step II: day of surgery-procaine penicillin } 600000 \mathrm{U} \text { intramuscularly } \\
\text { supplemented by crystalline penicillin } 600000 \mathrm{U} \text { intramuscularly } 1 \text { hour } \\
\text { before surgical procedure. }\end{array}$ \\
\hline & $\begin{array}{l}\text { Step III: for } 2 \text { days after surgery-procaine penicillin } 600000 \mathrm{U} \\
\text { intramuscularly each day. }\end{array}$ \\
\hline \multirow[t]{2}{*}{$1965^{9}$} & $\begin{array}{l}\text { Day of procedure: procaine penicillin } 600000 \mathrm{U} \text {, supplemented by } \\
\text { crystalline penicillin } 600000 \mathrm{U} \text { intramuscularly } 1-2 \text { hours before the } \\
\text { procedure. }\end{array}$ \\
\hline & $\begin{array}{l}\text { For } 2 \text { days after procedure: procaine penicillin } 600000 \mathrm{U} \text { intramuscularly } \\
\text { each day. }\end{array}$ \\
\hline $1972^{10}$ & $\begin{array}{l}\text { Procaine penicillin } G 600000 \mathrm{U} \text { mixed with crystalline penicillin } \mathrm{G} \\
200000 \mathrm{U} \text { intramuscularly } 1 \text { hour before procedure and once daily for } \\
\text { the } 2 \text { days after the procedure. }\end{array}$ \\
\hline $1977^{11}$ & $\begin{array}{l}\text { Aqueous crystalline penicillin G ( } 1000000 \mathrm{U} \text { intramuscularly) mixed } \\
\text { with procaine penicillin } \mathrm{G}(600000 \mathrm{U} \text { intramuscularly) } 30 \text { min to } 1 \text { hour } \\
\text { before procedure and then penicillin V } 500 \mathrm{mg} \text { orally every } 6 \text { hours for } \\
\text { eight doses. }\end{array}$ \\
\hline $1984^{12}$ & Penicillin $\vee 2 \mathrm{~g}$ orally 1 hour before; then, $1 \mathrm{~g} 6$ hours after initial dose \\
\hline $1990^{13}$ & $\begin{array}{l}\text { Amoxicillin } 3 \mathrm{~g} \text { orally } 1 \text { hour before procedure; then, } 1.5 \mathrm{~g} 6 \text { hours after } \\
\text { initial dose }\end{array}$ \\
\hline $199 /$. & Amoxicillin $2 \mathrm{~g}$ orally 1 hour before procedure \\
\hline $2007^{15}$ & Amoxicillin $2 \mathrm{~g}$ orally $30 \mathrm{~min}$ to 1 hour before procedure \\
\hline
\end{tabular}

${ }^{*}$ Reference number follows year.

tRegimens listed are for adults and represented the initial regimen listed in each version of the recommendations.

$\mathrm{IE}$, infective endocarditis.

and judicious use of current best evidence in making decisions about the care of individual patients' ${ }^{16}$ The AHA and other similar organisations instructed writing groups to do systematic literature searches, weigh evidence and classify each recommendation (typically as Classes I-III) and assign a strength to the recommendation based upon the available evidence (see further explanations of classes of recommendations and levels of evidence in refs. 15 and 17).

Various groups of experts in Europe and the USA were increasingly aware that there were not any clinical trials showing the effectiveness, or lack thereof, of antibiotic prophylaxis to prevent endocarditis. ${ }^{15}$ 17-19 In the early 2000s, the AHA Committee on Rheumatic Fever, Endocarditis and Kawasaki Disease began reviewing the available literature (predominantly from English language journals or from journals with English language summaries) on the role of antibiotics in preventing endocarditis. The decision was made to revise the guidelines, based around four reasons cited in box 1 and discussed in detail below.

Their first two reasons are related to the source and incidence of bacteraemia and to whether prophylaxis can reduce cases of IE that are (putatively) related to these bacteraemias. Specifically related to the oral cavity, transient bacteraemia (comprised primarily of viridans group streptococci (VGS) and also other oral microflora) likely occurs daily. An individual is more frequently
Box 1 Primary reasons for revision of the IE prophylaxis guidelines*

1. IE is much more likely to result from frequent exposure to random bacteraemias associated with daily activities than from bacteraemia caused by a dental, GI tract or GU tract procedure. 2. Prophylaxis may prevent an exceedingly small number of cases of IE, if any, in individuals who undergo a dental, GI tract or GU tract procedure.

3. The risk of antibiotic-associated adverse events exceeds the benefit, if any, from prophylactic antibiotic therapy.

4. Maintenance of optimal oral health and hygiene may reduce the incidence of bacteraemia from daily activities and is more important than prophylactic antibiotics for a dental procedure to reduce the risk of IE.

${ }^{*}$ From Wilson et al. ${ }^{15}$ Used with permission.

$\mathrm{IE}$, infective endocarditis; GI, gastrointestinal; GU, genitourinary.

exposed to random 'physiological' bacteraemias associated with normal daily activities such as chewing food or brushing teeth than from bacteraemia caused by a dental procedure. For example, Durack ${ }^{20}$ reviewed available data on the incidence of bacteraemia associated with manipulations in the oral cavity, and reported that for tooth extraction incidence ranged from $18 \%$ to $85 \%$, for periodontal surgery from $60 \%$ to $90 \%$ and for toothbrushing or irrigation from $7 \%$ to $50 \%$. The AHA writing group further reviewed data related to the incidence of bacteraemia associated with routine daily activities unrelated to a dental procedure. These activities included toothbrushing and flossing (20\%-68\% incidence of bacteraemia), use of wooden toothpicks (20\%-40\%), use of water irrigation devices $(7 \%-$ $50 \%)$ and chewing food $(7 \%-51 \%) .^{15}$

Various investigators and medical groups have concluded that the evidence relating endocarditis to a potential index procedure is mostly circumstantial, because only a small percentage of IE cases can be related back to such procedures. ${ }^{21-26}$

Furthermore, in reviewing case reports linking IE to a dental procedure IE, it has been observed that in many cases the onset of endocarditis occurred many months after the procedure (rather than weeks after) or that the causative agent was not a bacterial species that lives in the oral cavity.

Most people only visit a dentist one to two times per year, and so are only exposed to a bacteraemia related to dentist or dental hygienist manipulations on rare occasions, whereas they are exposed to transient bacteraemia from daily activities (eating, brushing, flossing) very frequently. Even though these daily transient bacteraemias are of low grade and of short duration, they are of high incidence. For example, Roberts calculated that brushing teeth twice a day for 1 year had 154000 times cumulative greater risk of exposure to bacteraemia than that resulting from a single tooth extraction. ${ }^{27}$ Lockhart and colleagues conducted a double-blind, placebo-controlled study looking at bacteraemia after toothbrushing, versus single-tooth extraction with amoxicillin prophylaxis versus single-tooth extraction with identical placebo. They surmised that toothbrushing has a risk for bacteraemia similar to that of tooth extraction, and that because of one's frequency of toothbrushing (compared with the frequency of having a dental extraction), it may be the greater threat for developing IE. ${ }^{28}$

It is clearly not realistic to administer prophylaxis against these random daily physiological bacteraemias. Thus, if prophylaxis is 
administered prior to a once-yearly or twice-yearly dental procedure, even if it were $100 \%$ effective, only an exceedingly small proportion of cases of IE would be prevented. ${ }^{15}$ 17-19 29

Good oral hygiene must not be downplayed. Lockhart and coinvestigators, in a separate analysis of the above-cited patient cohort, assessed several parameters of participants' oral health and hygiene and found that poor oral hygiene/health was associated significantly with IE-related bacteraemia after toothbrushing. ${ }^{30}$

It should be emphasised to patients that the maintenance of optimal oral health and hygiene and regular dentist visits may reduce the incidence of bacteraemia from brushing teeth, chewing food and similar daily activities, and thus are particularly important in reducing the risk of IE.

Additionally, there is the potential of adverse reactions associated with antibiotic use. However, the AHA is unaware of any fatal reactions to any of the antibiotic regimens they have recommended over the past 60 years. Therefore, in situations where prophylaxis prior to a dental procedure is warranted, a single dose of amoxicillin or ampicillin is safe for individuals who do not have a history of type I hypersensitivity reaction to a penicillin.

Finally, widespread use of antibiotics can lead to the emergence of resistant bacteria such as VGS. These bacteria are a part of the normal oral cavity flora and a common cause of endocarditis, and in fact the frequency of multidrug-resistant VGS has increased dramatically during the past 25-30 years. This in turn reduced the number of effective antibiotic options available for the treatment of an episode of IE. Antibiotic resistance has been characterised by the WHO as 'an increasingly serious threat to global public health'. ${ }^{31}$ For more information on antibiotic resistance, see the WHO's latest fact sheet on this topic (http://www.who.int/mediacentre/factsheets/fs194/en/).

In the past 10 years or so, the AHA, ${ }^{15}$ European Society of Cardiology (ESC), ${ }^{17}$ a consortium of French organisations ${ }^{18}$ and the UK's National Institute for Health and Care Excellence $(\mathrm{NICE})^{19}$ have published their revised guidelines concerning IE prophylaxis (see table 2). They have either eliminated the use of antibiotics for all patients undergoing a dental procedure ${ }^{19}$ or have significantly limited antibiotic prophylaxis to certain at-risk invasive dental procedures and certain at-risk patients. ${ }^{15} 17 \quad 18$ The number of cardiac conditions for which prophylaxis is reasonable has been reduced from previous iterations of the guidelines. In these current guidelines, prophylaxis is only recommended for patients at the highest risk for endocarditis and/ or highest risk of serious adverse outcomes from endocarditis.

All three sets of recommendations state that the patient groups from whom prophylaxis is reasonable include patients with a prosthetic cardiac valve or prosthetic material used for cardiac valve repair; patients who have previously had IE; and patients with certain types of congenital heart disease (CHD).

Patients with prosthetic valves/prosthetic material have a higher risk of IE as well as a higher risk of adverse outcomes (including reoperation) and a fourfold higher mortality than similar patients who have native valve IE..$^{15}$

Patients who have previously had endocarditis also have a greater risk for major complications, such as congestive heart failure or need for valve surgery, and increased mortality.

Although there are many types of CHD, most reports on children or adults with congenital defects suggest that those with complex cyanotic heart disease and those with postoperative palliative shunts, conduits or other prostheses have the highest risk for adverse events associated with IE as well as high mortality. If a congenital defect has been successfully repaired without residual defects, prophylaxis can be prescribed for the first 6 months after the repair in order to allow endothelialisation of the prosthetic material.

In addition to the three patient groups above, the AHA includes a fourth group-patients with a heart transplant who develop a valvulopathy (which is most likely to occur during episodes of cardiac rejection). Although the AHA guidelines acknowledge that there is no strong evidence to support this specific recommendation, IE in these patients can be associated with adverse outcomes including the need for reoperation and high mortality.

The list of dental procedures for which prophylaxis is recommended for the patient groups discussed above includes those

Table 2 Summary of organisational recommendations for prophylaxis for dental procedures with risk of gingival or mucosal trauma in patients with the highest incidence of IE and/or highest risk of adverse outcome from IE

\begin{tabular}{|c|c|c|}
\hline $\begin{array}{l}\text { Organisation } \\
\text { (reference \#) }\end{array}$ & Prophylaxis recommended* & Cardiac conditions \\
\hline$A H A^{15}$ & $\begin{array}{l}\text { Amoxicillin } 2 \mathrm{~g} \text { orally } 30-60 \mathrm{~min} \text { before the } \\
\text { procedure }\end{array}$ & $\begin{array}{l}\text { Prosthetic cardiac valve or prosthetic material used for cardiac valve repair } \\
\text { Previous IE } \\
\text { Congenital heart disease (CHD) } \\
\text { - Unrepaired cyanotic CHD, including palliative shunts and conduits } \\
\text { - Completely repaired congenital heart defect with prosthetic material or device, whether placed } \\
\text { by surgery or by catheter intervention, during the first } 6 \text { months after the procedure } \\
\text { - Repaired CHD with residual defects at the site or adjacent to the site of a prosthetic patch or } \\
\text { prosthetic device (which inhibit endothelialisation) } \\
\text { Cardiac transplantation recipients who develop cardiac valvulopathy }\end{array}$ \\
\hline $\mathrm{ESC}^{17}$ & $\begin{array}{l}\text { Amoxicillin or ampicillin } 2 \mathrm{~g} \text { orally or } \\
\text { intravenously } 30-60 \text { min before the procedure }\end{array}$ & $\begin{array}{l}\text { Prosthetic valve or prosthetic material used for cardiac valve repair } \\
\text { Previous IE } \\
\text { CHD, in particular, complex cyanotic heart disease and postoperative palliative shunts, conduits } \\
\text { or other prostheses. After surgical repair with no residual defects, prophylaxis for the first } \\
6 \text { months after the procedure until endothelialisation of the prosthetic material occurs. }\end{array}$ \\
\hline French $^{18}$ & $\begin{array}{l}3 \mathrm{~g} \text { amoxicillin orally in the hour before the } \\
\text { procedure }\end{array}$ & $\begin{array}{l}\text { Valvar prostheses (mechanical, homograft or bioprosthetic) } \\
\text { Non-operated cyanotic } \\
\text { CHD and pulmonary-systemic shunts } \\
\text { Previous IE }\end{array}$ \\
\hline $\mathrm{NICE}^{19}$ & None & None \\
\hline
\end{tabular}

${ }^{*}$ First choice, adult doses listed. For paediatric doses or alternative medications, see references.

AHA, American Heart Association; IE, infective endocarditis; NICE, National Institute for Health and Care Excellence. 
procedures that involve the manipulation of gingival tissue or the periapical region of teeth or perforation of the oral mucosa.

In the years subsequent to the French, American, European and UK groups changing their guidelines to eliminate some ${ }^{15} 1718$ or all ${ }^{19}$ prophylaxis recommendations associated with dental procedures, various studies have been undertaken to see if the incidence of IE has changed. Duval and colleagues conducted three population-based surveys in 1991, 1999 and 2008 in three French regions. ${ }^{1}$ Two of these 1-year surveys (1991 and 1999) had been conducted before the IE prophylaxis regimen was altered in 2002, and the third one a few years after the revised guidelines. They observed that there was no increase in oral streptococcal endocarditis in 2008 compared with the earlier surveys and concluded that these results support the reduction in the use of prophylaxis prior to dental procedures.

Temporal trend analyses of the incidence of VGS endocarditis in Olmsted County, Minnesota were done for the time period 1999 through $2010^{32}$ and again through the year 2013. ${ }^{33}$ Both times, it was observed that there was no increase in IE related to VGS from before to after the publication of the AHA prophylaxis guidelines. Other studies looking at IE hospitalisation rates across Canada (from 2002 to 2013) (4) $^{34}$ or in children in US hospitals (from 2003 to 2014$)^{35}$ showed that there was no change in hospitalisation rates associated with the 2007 publication of the US prophylaxis guidelines. Another study looked at hospitalisation rates in US Medicare recipients aged 65 and older from 1999 to 2010 and found that while the burden of IE is high in older adults, there was no increase in the rate of hospitalisation for or mortality from IE in the years following the changes in the AHA prophylaxis guidelines. ${ }^{36}$ A study by Thornhill and colleagues from the UK published in 2011 looked at the impact of the NICE guidelines which recommend complete elimination of IE antibiotic prophylaxis. ${ }^{37}$ This before and after study found that despite an almost $80 \%$ decrease in prescribing of antibiotic prophylaxis after the introduction of the NICE guidelines, there was no significant increase in the incidence of cases of deaths from IE in the 2 years after the guidelines.

Despite the studies cited above which did not show an impact of the various prophylaxis guidelines on the incidence of IE, two studies published in 2015 have shown an increased incidence. A study from the USA was undertaken to compare temporal trends in IE incidence, microbiology and outcomes before and after the change in the 2007 IE prophylaxis guideline. ${ }^{5}$ These investigators observed that there was a steady increase in the overall incidence of IE between 2007 and 2011. Further, they reported a significant rise in the incidence of streptococcal endocarditis since 2007 which they speculated could be related to the decrease in the use of IE prophylaxis since the guideline change. However, this study did not report speciation of streptococci, which may have included cases of non-VGS or possibly enterococci. Additionally, they stated that there had not been any increases in the rates of hospitalisation or of valve surgery since the 2007 guidelines.

Finally, a paper from the UK looked at the incidence of IE in England from 2000 to $2013 .^{38}$ This study was described by the authors as a 'more sophisticated reanalysis' of the paper they published in 2011. ${ }^{37}$ The 2011 paper looked before and for 2 years after the NICE guidelines were published, whereas the current study carried the 'after' portion of the study out to 5 years post-NICE. As in their previous analysis, there continued to be a substantial decrease in prescribing antibiotic prophylaxis, but in contrast to their earlier publication, there was a significant increase in IE. By the conclusion of the study in 2013, 35 more cases per month were reported than that would have been expected from the projected historical trend. They also found this increase to be significant for both patients at high risk of infection and at lower risk for IE. They were not able to collect meaningful data on the specific organisms and thus concluded that they could not show a causal link between the discontinuation of IE prophylaxis and the increase in incidence of IE. In spite of this, it is important to know they have seen an increase in IE incidence since the NICE guidelines were adopted. In a Lancet 'seminar' paper published recently, ${ }^{39}$ two UK researchers stated that the results of the 2015 paper by Dayer and colleagues $^{38}$ had created some uncertainty and that many UK cardiologists are deferring to the European and American society guidelines and prescribing IE prophylaxis to patients in the highest risk groups.

In summary, over the past several years, major changes have occurred in the use of antibiotic prophylaxis for prevention of IE in individuals with cardiac conditions prior to an invasive dental procedure. Current guidelines from Europe and the USA only recommend antibiotic prophylaxis for people with the highest risk for developing endocarditis and/or highest risk of serious adverse outcomes from endocarditis. This includes those individuals with a prosthetic valve/prosthetic material, those with a history of IE and those with certain congenital cardiac defect. Current guidelines from the UK have eliminated IE prophylaxis entirely. Who is right-the European and US approach, the UK approach or neither? This can only be answered by international collaboration to design the type of study needed to finally give an evidence-based answer to the question. Therefore, we strongly advocate for a multinational randomised controlled clinical trial that would include individuals from both developed countries and low/middle-income countries around the world. These studies are needed to ultimately define whether there is any role for antibiotic prophylaxis administered before certain invasive procedures to prevent IE. In the meantime, especially in light of data emerging from the UK, we believe that the approach taken by the ESC, the French and the AHA is reasonable.

Finally, we were asked to comment on a clinical case as one side of a debate. ${ }^{40}$ This was in reference to a 52-year-old woman who is scheduled to undergo double valve replacement surgery for severe mitral stenosis and severe aortic regurgitation. She has no other comorbidities. As part of the routine preoperative evaluation, a dental consultation is obtained. She is found to have dental caries in one premolar, and the dentist advises extraction of the tooth. We were asked the following question: 'Would you advise periprocedural infective endocarditis prophylaxis?'

The patient has severe mitral stenosis and severe aortic regurgitation. She does not have a cardiac condition which is considered to put her at the highest risk of serious adverse outcomes from endocarditis. Therefore, she is not a candidate for antibiotic prophylaxis before her dental procedure to prevent IE according to the criteria discussed above, and thus we would not advise periprocedural IE prophylaxis.

Competing interests None declared.

Provenance and peer review Commissioned; internally peer reviewed.

\section{REFERENCES}

1 Duval $X$, Delahaye F, Alla F, et al. AEPEI Study Group. Temporal trends in infective endocarditis in the context of prophylaxis guideline modifications: three successive population-based surveys. J Am Coll Cardiol 2012;59:1968-76.

2 Correa de Sa DD, Tleyjeh IM, Anavekar NS, et al. Epidemiological trends of infective endocarditis: a population-based study in Olmsted County, Minnesota [published 
correction appears in Mayo Clin Proc. 2010;85:772]. Mayo Clin Proc 2010;85:422-6.

3 Berlin JA, Abrutyn E, Strom BL, et al. Incidence of infective endocarditis in the Delaware Valley, 1988-1990. Am J Cardiol 1995;76:933-6.

4 Delahaye $F$, Goulet V, Lacassin F, et al. Characteristics of infective endocarditis in France 1991: a one year survey. Eur Heart J 1995;16:394-401.

5 Pant S, Patel NJ, Deshmukh A, et al. Trends in Infective Endocarditis Incidence, Microbiology, and Valve Replacement in the United States From 2000 to 2011 J Am Coll Cardiol 2015;65:2070-6.

6 Jones TD, Baumgartner L, Bellows MT, et al. (Committee on Prevention of Rheumatic Fever and Bacterial Endocarditis, American Heart Association). Prevention of rheumatic fever and bacterial endocarditis through control of streptococcal infections. Circulation 1955;11:317-20.

7 Rammelkamp CH Jr, Breese BB, Griffeath HI, Houser HB, et al. (Committee on Prevention of Rheumatic Fever and Bacterial Endocarditis, American Heart Association). Prevention of rheumatic fever and bacterial endocarditis through control of streptococcal infections. Circulation 1957;15:154-8.

8 Committee on Prevention of Rheumatic Fever and Bacterial Endocarditis, American Heart Association. Prevention of rheumatic fever and bacterial endocarditis through control of streptococcal infections. Circulation 1960;21:151-5.

9 Wannamaker LW, Denny FW, Diehl A, et al. (Committee on Prevention of Rheumatic Fever and Bacterial Endocarditis, American Heart Association). Prevention of bacterial endocarditis. Circulation 1965;31:953-4.

10 Rheumatic Fever Committee and the Committee on Congenital Cardiac Defects, American Heart Association. Prevention of bacterial endocarditis. Circulation 1972:46:S3-6.

11 Kaplan EL, Anthony BF, Bisno A, et al. (Committee on Rheumatic Fever and Bacterial Endocarditis, American Heart Association). Prevention of bacterial endocarditis. Circulation 1977;56:139A-43A

12 Shulman ST, Amren DP, Bisno AL, et al. (Committee on Rheumatic Fever and Infective Endocarditis, American Heart Association). Prevention of bacterial endocarditis: a statement for health professionals by the Committee on Rheumatic Fever and Infective Endocarditis of the Council on Cardiovascular Disease in the Young. Circulation 1984;70:1123A-7A.

13 Dajani AS, Bisno AL, Chung KJ, et al. Prevention of bacterial endocarditis: recommendations by the American Heart Association. JAMA 1990;264: 2919-22.

14 Dajani AS, Taubert KA, Wilson W, et al. r. Prevention of bacterial endocarditis: recommendations by the American Heart Association. JAMA 1997;277: 1794-801.

15 Wilson W, Taubert KA, Gewitz M, American Heart Association Rheumatic Fever, Endocarditis, and Kawasaki Disease Committee; American Heart Association Council on Cardiovascular Disease in the Young; American Heart Association Council on Clinical Cardiology, et al. Prevention of infective endocarditis: guidelines from the American Heart Association: a guideline from the American Heart Association Rheumatic Fever, Endocarditis, and Kawasaki Disease Committee, Council on Cardiovascular Disease in the Young, and the Council on Clinical Cardiology, Council on Cardiovascular Surgery and Anesthesia, and the Quality of Care and Outcomes Research Interdisciplinary Working Group. Circulation 2007;116:1736-54.

16 Sackett DL, Rosenberg WMC, Gray JAM, et al. Editorial: evidence based medicine: what it is and what it isn't. BMJ 1996;312:71-2.

17 Habib G, Hoen B, Tornos P, et al., ESC Committee for Practice Guidelines. Guidelines on the prevention, diagnosis, and treatment of infective endocarditis (new version 2009): the Task Force on the Prevention, Diagnosis, and Treatment of Infective Endocarditis of the European Society of Cardiology (ESC). Endorsed by the European Society of Clinical Microbiology and Infectious Diseases (ESCMID) and the International Society of Chemotherapy (ISC) for Infection and Cancer. Eur Heart J 2009;30:2369-413.

18 Danchin N, Duval X, Leport C. Prophylaxis of infective endocarditis: French recommendations 2002. Heart 2005;91:715-18.
19 National Institute for Health and Care Excellence (NICE). Prophylaxis against infective endocarditis. National Institute for Health and Clinical Excellence, 2008. (with 2016 update). http://www.nice.org.uk/CG64 (accessed 20 Dec 2016).

20 Durack DT. Prevention of infective endocarditis. N Engl J Med 1995;332:38-44.

21 van der Meer JTM, van Wijk W, Thompson J, et al. Efficacy of antibiotic prophylaxis for prevention of native-valve endocarditis. Lancet 1992;339:135-9.

22 Bayliss R, Clarke C, Oakley CM, et al. The microbiology and pathogenesis of infective endocarditis. Br Heart J 1983;50:513-19.

23 van der Meer JTM, Thompson J, Valkenburg HA, et al. Epidemiology of bacterial endocarditis in the Netherlands. II. Antecedent procedures and use of prophylaxis. Arch Intern Med 1992;152:1869-73.

24 Pogrel MA, Welsby PD. The dentist and prevention of infective endocarditis. Br Dent J 1975;139:12-16.

25 Math RS, Sharma G, Kothari SS, et al. Prospective study of infective endocarditis from a developing country. Am Heart J 2011;162:633-8.

26 Chen PC, Tung YC, Wu PW, et al. Dental Procedures and the Risk of Infective Endocarditis. Medicine 2015;94:e1826-31.

27 Roberts GJ. Dentists are innocent! 'Everyday' bacteremia is the real culprit: a review and assessment of the evidence that dental surgical procedures are a principal cause of bacterial endocarditis in children. Pediatr Cardiol 1999;20:317-25.

28 Lockhart PB, Brennan MT, Sasser HC, et al. Bacteremia associated with toothbrushing and dental extraction. Circulation 2008;117:3118-25.

29 Duval X, Alla F, Hoen B, et al. Estimated risk of endocarditis in adults with predisposing cardiac conditions undergoing dental procedures with or without antibiotic prophylaxis. Clin Infect Dis 2006;42:e102-7.

30 Lockhart PB, Brennan MT, Thornhill M, et al. Poor oral hygiene as a risk factor for infective endocarditis-related bacteremia. J Am Dent Assoc 2009;140:1238-44.

31 World Health Organization. Global action plan on antimicrobial resistance. 2015. http://apps.who.int/iris/bitstream/10665/193736/1/9789241509763_eng.pdf?ua=1 (accessed 20 Dec 2016).

32 Desimone DC, Tleyjeh IM, Correa de Sa DD, et al. Incidence of infective endocarditis caused by viridans group Streptococci before and after publication of the 2007 American Heart Association's endocarditis prevention guidelines. Circulation 2012;126:60-4.

33 DeSimone DC, Tleyjeh IM, Correa de Sa DD, et al. for the Mayo Cardiovascular Infections Study Group. Incidence of infective endocarditis due to viridans group streptococci before and after the 2007 American Heart Association's prevention guidelines: an extended evaluation of the Olmsted County, Minnesota, population and nationwide inpatient sample. Mayo Clin Proc 2015;90:874-81.

34 Mackie AS, Liu W, Savu A, et al. Infective endocarditis hospitalizations before and after the 2007 American Heart Association prophylaxis guidelines. Can J Cardiol 2016;32:942-8

35 Bates KE, Hall M, Shah SS, et al. Trends in infective endocarditis hospitalisations at United States children's hospitals from 2003 to 2014: impact of the 2007 American Heart Association antibiotic prophylaxis guidelines. Cardiol Young 2016:15:1-5.

36 Bikdeli B, Wang Y, Kim N, et al. Trends in hospitalization rates and outcomes of endocarditis among Medicare beneficiaries. J Am Coll Cardiol 2013;62:2217-26.

37 Thornhill MH, Dayer MJ, Forde JM, et al. Impact of the NICE guideline recommending cessation of antibiotic prophylaxis for prevention of infective endocarditis: before and after study. BMJ 2011;342:d2392.

38 Dayer MJ, Jones S, Prendergast $B$, et al. Incidence of infective endocarditis in England, 2000-13: a secular trend, interrupted time-series analysis. Lancet 2015;385:1219-28.

39 Cahill TJ, Prendergast BD. Infective endocarditis. Lancet 2016;387:882-93.

40 Taubert K, Wilson W. Interactive clinical case: To give, or not to give, infective endocarditis prophylaxis. Approach 1: Prophylaxis not recommended. BMJ Blogs. Heart Asia. http://blogs.bmj.com/heartasia/2016/11/30/interactive-clinical-caseto-give-or-not-to-give-infective-endocarditis-prophylaxis/. (accessed 29 Jan 2017). 